\title{
Redução do Absenteísmo Através da Gestão da Agenda e do Trabalho em Rede
}

\author{
Canelada, Haline Fernanda; Levorato, Cleice Daiana; Corte, Rachel I.A. da Silveira; \\ Diniz, Emanoela E. dos Santos \\ Hospital Estadual Américo Brasiliense — halinefernanda@yahoo.com.br
}

\begin{abstract}
INTRODUÇÃO: o modelo do sistema público de saúde no Brasil, universal, integral e gratuito, foi legitimado pela Constituição de 1988, regulamentado pelas leis 8.080 e 8.142 , de 1990 , e fundamentando nos princípios da universalidade de acesso, integralidade, equidade, regionalização, hierarquização e participação social.(BRASIL, 1988) Contudo, sabe-se que a rede de saúde no Brasil convive em um descompasso entre oferta e acesso, o que torna a consolidação do SUS utópica. na contramão desta realidade brasileira, um Ambulatório Médico de Especialidades (AME), no interior do estado de São Paulo, iniciou um trabalho voltado à gestão das agendas, posicionando-se não como um mero ofertador de serviços, mas sim como instrumento potencializador e provocador do trabalho em rede. OBJETIVOS: Garantir o acesso dos usuários através da gestão da agenda, com confirmação de comparecimento, flexibilizando a vinda destes perante atendimento com horário agendado e reduzir o absenteísmo a uma taxa menor que 5\%. METODOLOGIA: na primeira etapa do estudo foi realizada uma análise quantitativa dos relatórios de produtividade do período de janeiro a novembro de 2013 , avaliou-se a quantidade de atendimentos agendados (consultas e exames) e a taxa de absenteísmo destas (com uma variação entre 10 a $30 \%$ ). a partir dos dados coletados e quantificados, por meio de ligações telefônicas, foi estabelecido como rotina de trabalho, o contato com os usuários agendados para confirmação de presença em consultas e exames com maior demanda. As especialidades trabalhadas neste período foram: Cardiologia, Cirurgia Vascular, Endocrinologia, Ginecologia, Oftalmologia, Ortopedia e Pneumologia, além do exame de Ultrassonografia. Assim, caso o usuário não confirmasse presença antecipadamente o serviço de saúde poderia ofertar esta vaga desistente a outro, não havendo desperdícios e atendendo a demanda da região. Concomitante a isto, foram realizadas reuniões com os colegiados gestores, de maneira a apresentar aos gestores municipais 0 ambulatório, os agendamentos, a taxa de absenteísmo, perda primária e uso de vagas de "bolsões" por cada município, visando pactuações e corresponsabilidade entre os serviços. RESULTADOS:Embora os dados quantitativos e relacionais sejam recentes, com a otimização das agendas das especialidades citadas acima, foi possível identificar que em $62 \%$ das especialidades trabalhadas o percentual de faltas (taxa de absenteísmo) diminuiu entre 2 e $4 \%$. Entretanto, apesar dos resultados serem positivos, está em construção um questionário caracterizador do motivo das ausências e futuramente, serão estabelecidas estratégias perante estas informações. CONCLUSÃO: um estudo realizado por Bender (2010) constatou que o aumento do absenteísmo na atenção secundária, impacta em uma possível complicação do quadro de saúde do usuário, interferindo na continuidade do seu tratamento e ainda no aumento da demanda na rede básica, devido ás complicações de saúde. por isso é importante ressaltar a indissociabilidade entre gestão e atenção e entender 0 trabalho em rede como uma engrenagem produtora de articulações e ações complementares, que objetivem facilitar o acesso dos usuários ao serviço de saúde público.
\end{abstract}

Canelada, Haline Fernanda; Levorato, Cleice Daiana; Corte, Rachel I.A. da Silveira; Diniz, Emanoela E. dos Santos. Redução do Absenteísmo Através da Gestão da Agenda e do Trabalho em Rede. In: Anais do Congresso Internacional de Humanidades \& Humanização em Saúde [= Blucher Medical Proceedings, num.2, vol.1]. São Paulo: Editora Blucher, 2014. ISSN 2357-7282

DOI 10.5151/medpro-cihhs-10458 